\title{
¿Jugando con el tiempo? Seguridad de la ampliación del intervalo entre dosis de la vacuna Pfizer (BNT162b2). El caso de Colombia
}

Ampliar el intervalo de la vacunación más allá de los 21 días con la segunda dosis de la vacuna BNT162b2 (Pfizer) ha sido una decisión polémica, que le ha suscitado al Ministerio de Salud y al Gobierno de Colombia un sinfín de críticas, a tal punto que ha pasado al ámbito legal(1). Lo cual, probablemente se hubiera atenuado si se hace una divulgación mediática más acertada, centrada en los estudios existentes y tomando como referencia el Sistema de Salud del Reino Unido.

Aunque parezca una idea pionera del Ministerio de Salud de Colombia, la medida de ampliar el intervalo entre la primera y la segunda dosis, fundamentada ante la escasez de las vacunas y/o en la limitación de los recursos para adquirirlas, fue aplicada en el mes de diciembre del 2020 por el Comité Conjunto de Vacunación e Inmunización del Reino Unido, que informó que los intervalos de dosificación podrían extenderse hasta 12 semanas para optimizar la cobertura de la primera dosis(2). Esta decisión se tomó en el contexto del rápido aumento de la incidencia del SARS-CoV-2, asociado con la aparición de la variante Alpha altamente transmisible y su posterior propagación dentro de los centros de atención a largo plazo a partir de noviembre de $2020^{(3,4)}$. Lo anterior, impulsó diversos proyectos de investigación relacionados directa o indirectamente con la seguridad de dicha ampliación del intervalo entre dosis de vacunas, contrario al esquema inicial propuesto por el fabricante de 21 días(5).

En ese sentido, en un estudio realizado en Inglaterra a una muestra de 10.412 personas con edades $\geq 65$ años, se demostró que, a partir de los 28 días, luego de la primera dosis el riesgo de ingreso a centro hospitalario se reduce sustancialmente; en datos, esto se traduce de la siguiente forma: entre 28 y 34 días la eficacia es del $56 \%$ (IC del 95\%: 19-76) y entre los 35 y 48 días esta es de 62\% (IC del 95\%: 23-81), además de ello, los autores indican que el efecto protector se mantiene más allá de las 7 semanas( ${ }^{(6)}$, aunque se aclara que la muestra es menor a partir de allí, por lo que la estimación pierde cierta confiabilidad.

Otro estudio que apoya este aumento en el intervalo entre dosis, es el efectuado en Escocia, que, al ser parte de Reino Unido, también vacunó con la segunda dosis a gran parte de su población 12 semanas después de la primera. En este se comprobó que el ingreso a centros hospitalarios se redujo un 91\% (IC del 95\%: 85-94) a los 28-34 días después de la primera dosis, sin embargo, la evidencia más allá de este tiempo debe complementarse con más estudios epidemiológicos, según manifiestan los autores(4). La anterior investigación es respaldada por una llevada a cabo en Israel, en una muestra de 596.618 individuos, donde sus hallazgos arrojaron que el 74\% mostró efectividad entre 14 y 20 días y de 78\% entre 21 y 27 días después de una única dosis de Pfizer(7); de este estudio es necesario resaltar, que se encuentra publicado en una plataforma de Preprint.

En la Figura 1 se grafican los valores de reducción de ingreso a centros hospitalarios, luego de 7 o más semanas de aplicarse la primera dosis de Pfizer en el estudio en mención con población escocesa(5).

Es evidente que existe información destacable que respalda la decisión del Ministerio de Salud de Colombia. No obstante, es recomendable la realización de un estudio en una muestra controlada en el territorio nacional, con la intención de dar más sustento a la ampliación del intervalo entre la primera y segunda dosis, teniendo en cuenta que al día de hoy existen innumerables variantes, que claramente son diferentes a las que circulan en Israel o Reino Unido. Por lo tanto, los autores de este texto recomiendan que el periodo de vacunación entre la primera y segunda dosis no sobrepase las 6 semanas. 


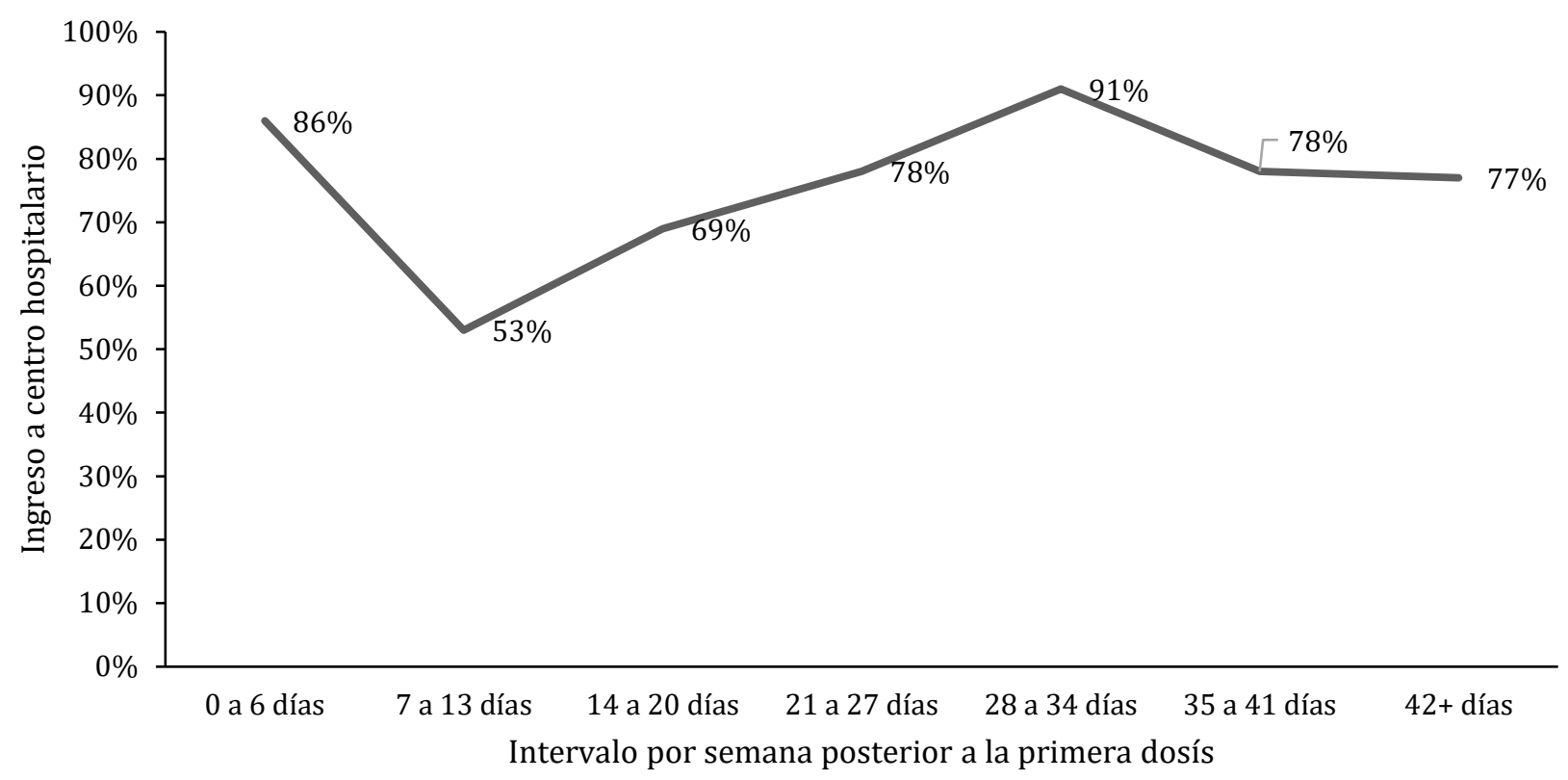

Figura 1. Reducción porcentual del ingreso a centro hospitalario posterior a la aplicación de la primera dosis de la vacuna Pfizer, con aumento gradual de una. Información tomada y editada de Vasileiou et al(5).

Finalmente, en ausencia de una segunda dosis disponible a los 21 días, a manera de reflexión, le preguntamos a los lectores lo siguiente: ¿Qué resulta más conveniente, tener a 10 personas vacunadas con una dosis o tener a 5 con dos dosis y a 5 sin ninguna de estas? En todo caso, ya sea con una o con las dosis aplicadas de esta vacuna o cualquiera de las otras existentes, es imprescindible que se complemente la protección con medidas preventivas no farmacéuticas como lo son: el distanciamiento social, el uso de tapabocas, el lavado de manos frecuentes, entre $\operatorname{otros}^{(8)}$.

Oskarly Pérez-Anaya ${ }^{*}$ orcid.org/0000-0002-0701-7847

Javier Hernández-Blanco'1 orcid.org/0000-0003-0473-8814

Juan Carlos de Jesús Correa-Palacio' orcid.org/0000-0001-5020-7868

1. Facultad de Ciencias de la Salud, Universidad del Magdalena. Santa Marta, Colombia.

Conflicto de intereses: Ninguno declarado por los autores.

*Autor de correspondencia
Oskarly Pérez Anaya
e-mail: oskperez123@gmail.com

\section{Referencias}

1. ElTiempo.com. Invidente ganó tutela y recibió segunda dosis de Pfizer contra covid. 2021. Disponible en: https://www.eltiempo.com/colombia/otras-ciudades/invidente-gano-tutela-y-recibio-segunda-dosis-de-pfizer-contra-covid603356

2. GOV.UK. Independent report: Optimising the COVID-19 vaccination programme for maximum short-term impact. 2020. Disponible en: https://www.gov.uk/government/publications/prioritising-the-first-covid-19-vaccine-dose-jcvistatement/optimising-the-covid-19-vaccination-programme-for-maximum-short-term-impact

3. Krutikov M, A Hayward A, Shallcross L. Spread of a variant SARS-CoV-2 in long-term care facilities in England. N Engl J Med. 2021;384(17):1671-3. Disponible en: https://www.nejm.org/doi/full/10.1056/NEJMc2035906

4. GOV.UK. Investigation of novel SARS-CoV-2 variants of concern: technical briefings. 2020. Disponible en: https://www.gov.uk/government/publications/investigation-of-novel-sars-cov-2-variant-variant-of-concern-20201201

5. Vasileiou E, Simpson CR, Shi T, Kerr S, Agrawal U, Akbari A, et al. Interim findings from first-dose mass COVID-19 vaccination rollout and COVID-19 hospital admissions in Scotland: a national prospective cohort study. The Lancet. 2021;397(10285):1646-57. DOI: 10.1016/S0140-6736(21)00677-2. 
6. Shrotri M, Krutikov M, Palmer T, Giddings R, Azmi B, Subbarao S, et al. Vaccine effectiveness of the first dose of ChAdOx1 nCoV19 and BNT162b2 against SARS-CoV-2 infection in residents of long-term care facilities in England (VIVALDI): a prospective cohort study. The Lancet Infectious Diseases. 2021. DOI: 10.1016/S1473-3099(21)00289-9.

7. Aran D. Estimating real-world COVID-19 vaccine effectiveness in Israel using aggregated counts. medRxiv. 2021. DOI: 10.1101/2021.02.05.21251139.

8. Shrotri M, Fragaszy E, Geismar C, Nguyen V, Beale S, Braithwaite I, et al. Spike-antibody responses to ChAdOx1 and BNT162b2 vaccines by demografics and clinical factors(Virus Watch study). Medrxiv. 2021. DOI: 10.1101/2021.05.12.21257102. 